\title{
Successful Use of Rocuronium and Sugammadex in a Patient with Myasthenia Gravis Undergoing Cervical Anterior Fusion: A Case Report
}

\author{
Ki Tae Jung ${ }^{1}$, Keum Young $\mathrm{So}^{2}$, Hyeon Song ${ }^{3}$, Sang Hun Kim ${ }^{4}$ \\ ${ }^{I}$ Associate Professor, Department of Anesthesiology and Pain Medicine, Chosun University, School of Medicine, \\ Republic of Korea \\ ${ }^{2}$ Professor, Department of Anesthesiology and Pain Medicine, Chosun University, School of Medicine, Republic \\ of Korea \\ ${ }^{3}$ Resident, Department of Anesthesiology and Pain Medicine, Chosun University Hospital, Republic of Korea \\ ${ }^{4}$ Associate Professor, Department of Anesthesiology and Pain Medicine, Chosun University, School of Medicine, \\ Republic of Korea
}

"Corresponding Author: Sang Hun Kim, Department of Anesthesiology and Pain Medicine, Chosun University, School of Medicine, Republic of Korea, Email: ksh3223@chosun.ac.kr

\begin{abstract}
The anesthetic management of patients with myasthenia gravis (MG) is usually challenging in elective surgery. Patients with MG exhibit a higher sensitivity to neuromuscular blockers, and very careful drug titrations were required under closely neuromuscular monitoring if neuromuscular blocker is essential for surgery and anesthesia. Patients are at risk of postoperative residual curarization if nondepolarizing neuromuscular blockers are used. So, anesthesiologists prefer spontaneous recovery and extubation after demonstration of adequate parameters. Nowadays some author recommended using sugammadex as a safe and reliable option for reversal of neuromuscular blocker in patients with MG. We present a case of woman receiving rocuronium under train-of-four monitoring for anterior fusion due to herniated cervical disc with $M G$, and she was subsequently reversed with sugammadexand extubated on postoperative successfully without any respiratory problems.
\end{abstract}

Keywords: Myasthenia gravis, Rocuronium, Spine surgery, Sugammadex, Train-of-four.

\section{INTRODUCTION}

Myasthenia gravis (MG) is an autoimmune disorder caused by failure of transmission of the neuromuscular junction leads to an unpredictable response to neuromuscular blockers, which is twice common in women than men [1-3]. MG is characterized by weakness and fatigue of skeletal muscle that it worsens with repetitive exercise while it improves with restore after administration of anticholinesterase medication [4, 5]. Surgery and anesthesia in patients with myasthenia gravis is associated with markedly increased risk of death and post-operative complications, including prolonged ventilation in intensive care $[5,6]$. Patients with $\mathrm{MG}$ exhibit a higher sensitivity to neuromuscular blockers and very careful drug titrations were required[7]. Patients are at risk of postoperative residual curarization if non depolarizing neuromuscular blockers are used. Therefore, neuromuscular blocker should be avoided, or shorter-acting drugs may chose under closely neuromuscular monitoring if neuromuscular blocker is essential for surgery and anesthesia [8]. In addition, anesthesiologists prefer spontaneous recovery and extubation after demonstration of adequate parameters (e.g., head life, tongue protrusion) [9, 10]. Nowadays some author recommended using sugammadex as a safe and reliable option for reversal of neuromuscular blocker in patients with MG $[3,11]$.

We present a case of woman receiving rocuronium for anterior fusion for herniated cervical disc with MG, and she was subsequently reversed with sugammadex and extubated on postoperative successfully without any respiratory problems. 


\section{CASE REPORT}

A55 year old woman $(60 \mathrm{~kg})$ underwent anterior fusion for herniated cervical disc. Her past medical history included a diagnosis of myasthenia gravis, diagnosed 7 years previously for which she was taking180 (60 x 3) $\mathrm{mg}$ pyridostigmine daily. After premedication with intramuscular midazolam $2.5 \mathrm{mg}$ and her usual dose of pyridostigmine $30 \mathrm{~min}$ prior to the induction of anesthesia, she was transported to the operating room. Prior to the induction of anesthesia, the standard patient monitoring devices such as an electrocardiogram, noninvasive blood pressure, end-tidal partial pressure of carbon dioxide $\left(\mathrm{ETCO}_{2}\right)$, and peripheral pulse oximetry were applied. And then, TOF-Watch ${ }^{\circledR}$ SX (Organ on, Dublin, Ireland) was applied for assessment of neuromuscular function by acceleromyography of the adductor pollicis muscle with Train-ofFour (TOF) according to the manufacturer's recommendation. Anesthesia was induced with remifentanil and propofol at target effect-site concentrations of $3.0 \mathrm{ng} / \mathrm{ml}$ and $3.0 \mu \mathrm{g} / \mathrm{ml}$ with a target-controlled infusion pump (Orchestra®; Fresenius Vial, Brezins, France). One minute after equilibration of the target plasma and effect-site concentrations of propofol and remifentanil, the supramaximal stimulus current (30 $\mathrm{mA})$ needed to achieve the maximal response of adductor pollicis muscle was obtained. Video-scope-assisted endotracheal intubation was performed after injection of rocuronium $25 \mathrm{mg} \quad(0.4 \mathrm{mg} / \mathrm{kg}$, ideal body weight) over 5 to 10 seconds with pretreatment of lidocaine $30 \mathrm{mg}$. For the maintenance of anesthesia, the target effect -site concentration of propofol and remifentanil was adjusted to maintain mean blood pressure less than $20 \%$ change and the bispectral index score in the range of 40 to 60 . The settings of mechanical ventilation with $50 \%$ oxygen-air mixture were also adjusted to maintain the $\mathrm{ETCO}_{2}$ between $35-45 \mathrm{mmHg}$. Additional rocuronium $5 \mathrm{mg}$ was used to maintain neuromuscular blockade less than TOF of 0.5 . The surgery lasted for 3.75 hours, during which time six boluses of rocuronium $5 \mathrm{mg}$ were given. The neuromuscular block was reversed with Sugammadex $3 \mathrm{mg} / \mathrm{kgat}$ the end of the surgery, at which TOF ratio was 0.64. She was successfully extubated without problem and transferred to the recovery room after confirming a TOF ratio of 0.9.Postoperatively she was managed in a high dependency setting with close monitoring of respiration, swallow and cough. Pyridostigmine was continued at the preoperative dose. He was discharged without any complications on postoperative 4 days.

\section{DisCUSSION}

The use of neuromuscular blockers in patients with MG has been a controversial topic, and it is difficult to determine the optimal amount of muscle relaxants required in these patients. Hence, there is an increasing trend of no neuromuscular blocker techniques in such patients who undergo surgery [12], but neuromuscular blockers should not be avoided in these patients if they require endotracheal intubation[11].

Non-depolarizing neuromuscular blockers have been known to be sensitive in patients with MG [7].The more severe disease and the higher the dose of pyridostigmine, the more sensitive the patient was toward non depolarizing NMBA [13]. We may chose shorter-acting neuromuscular blockers and use them under closely neuromuscular monitoring if neuromuscular blocker is essential for surgery and anesthesia [8]. When required, small doses (10 $-25 \%$ of ED 95) of intermediate-acting neuromuscular blockers are titrated for both intubation and surgical relaxation[8]. However, roughly $50 \%$ of the standard dose is probably adequate, and nearly all patients have a prolonged recovery [14]. Rocuronium 0.15 $\mathrm{mg} / \mathrm{kg}$, which is $50 \%$ of $\mathrm{ED}_{95}$, resulted in complete neuromuscular block within 120s, while it only produced $30-50 \%$ neuromuscular block within $240 \mathrm{~s}$ in normal patients [15]. In addition, $25 \%$ recovery of neuromuscular transmission occurred after $20 \mathrm{~min}$, while it was more rapid in normal patients [15]. Thus, they suggested that neuromuscular transmission must be monitored carefully in order to titrate the required dose of rocuronium and to ensure complete reversal of neuromuscular block [15].

For recovery from anesthesia in patients with MG, some author recommended using sugammadex as a safe and reliable option for reversal of neuromuscular blocker in patients with MG $[3,11,16]$, whether or not to reverse residual neuromuscular blockade at the end of surgery is controversial [8].The administration of sugammadex for reversal of neuromuscular 
blocker is useful to eliminate the risk of residual neuromuscular blockade in patients with $\mathrm{MG}$ [17]. Most case reports showed that neuromuscular blocker reversal using sugammadex seemed to be a safe, rapid, efficient, and reliable option without signs of postoperative residual neuromuscular block in patients with MG [17-21].

Some cases may require higher dose of rocuronium for rapid sequence induction and patient's safety during intraoperative period in patients with MG. A single bolus of rocuronium $0.5 \mathrm{mg} / \mathrm{kg}$ administered to facilitate tracheal intubation was required no maintenance doses of rocuronium, and the neuromuscular blockade was considered adequate throughout surgery [3]. Even though deep rocuronium-induced neuromuscular blockade was also effectively and safely reversed after administration of sugammadex $2 \mathrm{mg} / \mathrm{kg}$ at TOF ratio of 0.3 , and TOF ratio was reached 0.92 within 3 min after its administration as enough time as prompt weaning from mechanical ventilation postoperatively [3].The neuromuscular function after injection of rocuronium $0.3 \mathrm{mg} / \mathrm{kg}$ was rapidly recovered after administration of sugammadex $2 \mathrm{mg} / \mathrm{kg}$ in patients with MG [22]. In addition, Casarotti et al. [23] also suggested that full-dose rocuronium and reversal with sugammadex was the best combination that reconciled the need for rapid onset neuromuscular block while allowing a fast, effective, and reliable reversal at the end of surgery [23].

There is controversy whether cholinesterase inhibitor medication should be continued until the time of the operation, if patients are reliant on their cholinesterase inhibitor medication it should probably be continued perioperatively [4]. Continuation of cholinesterase inhibitors preoperatively does not affect the efficacy of the reversal of neuromuscular block by sugammadex and therefore optimal muscle function is preserved [17].

In this case, we continued her usual dose of pyridostigmine and performed neuromuscular block by rocuronium $0.4 \mathrm{mg} / \mathrm{kg}$. We gave rocuronium $5 \mathrm{mg}$ as additional bolus doses during anesthesia to maintain neuromuscular blockade less than TOF of 0.5 under monitoring of TOF ratio. For reversal, our patient received sugammadex $2 \mathrm{mg} / \mathrm{kg}$ which provided adequate reversal of rocuronium-induced neuromuscular block, which was confirmed by TOF ratio or 0.9 .

\section{CONCLUSiON}

To the best of our knowledge, this is the first reported case in the literature in which sugammadex was given in patient with $\mathrm{MG}$ undergoing cervical anterior fusion. Sugammadex provide effective reversal of rocuronium-induced neuromuscular block, which was titrated monitoring of neuromuscular function, in patients with MG well-controlled by continuation treatment of pyridostigmine until day surgery. Thus, we suggest that rocuroniuminduced neuromuscular block should be titrated monitoring of neuromuscular function, and administration of sugammadex could be routinely considered as part of the anesthesia management in patients with MG.

\section{REFERENCES}

[1] Naguib M, el Dawlatly AA, Ashour M, Bamgboye EA. Multivariate determinants of the need for postoperative ventilation in myasthenia gravis. Can J Anaesth 1996; 43:1006-13.

[2] Gilhus NE, Owe JF, Hoff JM, Romi F, Skeie GO, Aarli JA. Myasthenia gravis: a review of available treatment approaches. Autoimmune Dis 2011;2011:847393.

[3] Argiriadou H, Anastasiadis K, Thomaidou E, Vasilakos D. Reversal of neuromuscular blockade with sugammadex in an obese myasthenic patient undergoing thymectomy. J Anesth 2011;25:316-7.

[4] Conti-Fine BM, Milani M, Kaminski HJ. Myasthenia gravis: past, present, and future. J Clin Invest 2006;116:2843-54.

[5] Rudzka-Nowak A, Piechota M. Anaesthetic management of a patient with myasthenia gravis for abdominal surgery using sugammadex. Arch Med Sci 2011;7:361-4.

[6] Dillon FX. Anesthesia issues in the perioperative management of myasthenia gravis. Semin Neurol 2004;24:83-94.

[7] Baraka A. Anaesthesia and myasthenia gravis. Can J Anaesth 1992;39:476-86.

[8] Elsharkawy HA, Galway U. Anesthetic management of direct laryngoscopy and dilatation of subglottic stenosis in a patient with severe myasthenia gravis. Case Rep Anesthesiol 2012;2012:217561.

[9] Baraka A, Taha S, Yazbeck V, Rizkallah P. 
Vecuronium block in the myasthenic patient. Influence of anticholinesterase therapy. Anaesthesia 1993;48:588-90.

[10] O'Flaherty D, Pennant JH, Rao K, Giesecke AH. Total intravenous anesthesia with propofol for transsternal thymectomy in myasthenia gravis. J Clin Anesth 1992;4:241-4.

[11] Schaller SJ, Fink H. Sugammadex as a reversal agent for neuromuscular block: an evidencebased review. Core Evid 2013;8:57-67.

[12] Singh P, Poopalalingam R. Anaesthetic management of bronchopleural fistula in a patient with myasthenia gravis. Singapore Med J 2011;52:e100-1.

[13] Nilsson E, Meretoja OA. Vecuronium doseresponse and maintenance requirements in patients with myasthenia gravis. Anesthesiology 1990;73:28-32.

[14] Blichfeldt-Lauridsen L, Hansen BD. Anesthesia and myasthenia gravis. Acta Anaesthesiol Scand 2012;56:17-22.

[15] Baraka A, Haroun-Bizri S, Kawas N, Hajjar AM, Kawkabani N. Rocuronium in the myasthenic patient. Anaesthesia 1995; 50:1007.

[16] Vymazal T, Krecmerova M, Bicek V, Lischke R. Feasibility of full and rapid neuromuscular blockade recovery with sugammadex in myasthenia gravis patients undergoing surgery a series of 117 cases. Ther Clin Risk Manag 2015;11:1593-6.
[17] de Boer HD, van Egmond J, Driessen JJ, Booij LH. Sugammadex in patients with myasthenia gravis. Anaesthesia 2010;65:653.

[18] Unterbuchner C, Fink H, Blobner M. The use of sugammadex in a patient with myasthenia gravis. Anaesthesia 2010;65:302-5.

[19] Petrun AM, Mekis D, Kamenik M. Successful use of rocuronium and sugammadex in a patient with myasthenia. Eur J Anaesthesiol 2010; 27:917-8

[20] Rudzka-Nowak A, Piechota M. Anaesthetic management of a patient with myasthenia gravis for abdominal surgery using sugammadex. Archives of Medical Science 2011;7:361-4.

[21] Garcia V, Diemunsch P, Boet S. Use of rocuronium and sugammadex for caesarean delivery in a patient with myasthenia gravis. Int J Obstet Anesth 2012;21:286-7.

[22] Sungur Ulke Z, Yavru A, Camci E, Ozkan B, Toker A, Senturk M. Rocuronium and sugammadex in patients with myasthenia gravis undergoing thymectomy. Acta Anaesthesiol Scand 2013;57:745-8.

[23] Casarotti P, Mendola C, Cammarota G, Della Corte F. High-dose rocuronium for rapidsequence induction and reversal with sugammadex in two myasthenic patients. Acta Anaesthesiol Scand 2014;58:1154-8

Citation: Ki Tae Jung, Keum Young So, Hyeon Song, Sang Hun Kim. Successful Use of Rocuronium and Sugammadex in a Patient with Myasthenia Gravis Undergoing Cervical Anterior Fusion: A Case Report. ARC Journal of Anesthesiology. 2017;2(4):32-35. doi: dx.doi.org/10.20431/2455-9792.0204005.

Copyright: (C) 2017 Authors. This is an open-access article distributed under the terms of the Creative Commons Attribution License, which permits unrestricted use, distribution, and reproduction in any medium, provided the original author and source are credited. 